\title{
معالجة انحراف السلوك الاجتماعي لاى المراهقين
}

\section{Dealing with social misbehaviors in teenagers}

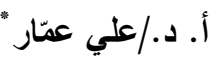

\section{ملخص}

يعد ثالوث (المرض - الفقر - الجهل) من الظواهر الاجتماعية البارزة التي غالباً ما تكون مرتبطة ببعضها

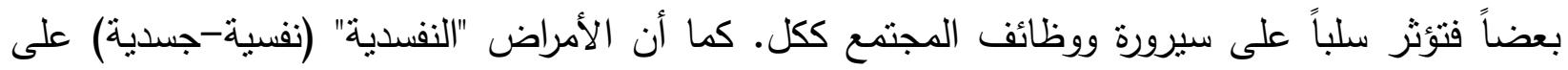
اختلاف أنواعها، ودرجة العناية بها هي من دلائل اهتمام المجتمع بأفراده وتوفير الرعاية لهم، من خلال

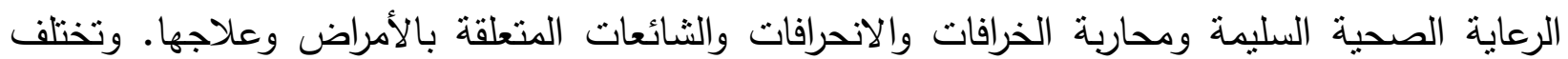

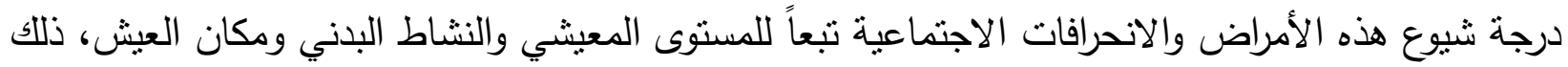

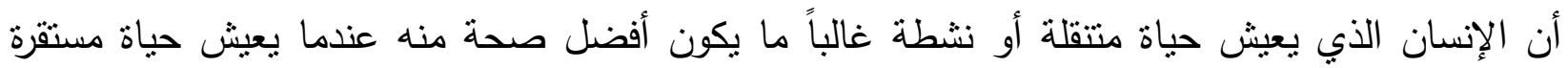
وساكنة لا حركة فيها ولا نشاط. لذا يقع على مؤسسات التربية والتعليم بمختلف مستوياتها واجب نشر لنائر العادات الصحية السليمة والتعويد على النظافة، والتغذية الصحية، والرياضة البدنية، والتعريف بواجبات الأمومة وتوعيتها، والعناية بالمرضى، واتقاء العدوى ومكافحة الانحرافات والخرافات الاجتماعية المتعلقة بالأمراض وانتشارها والثعوذة والسحر والدجل إلخ من أساليب منحرفة ومضللة.

\section{تعريف انحراف السلوك الاجتماعي}

يعرف انحراف السلوك الاجتماعي ببساطة بأنه "خلل في بناء الشخصية يحول دون توافق المنحرف مع

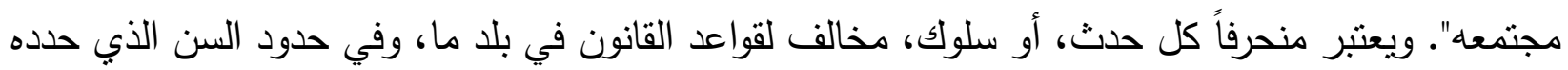
له ذلك القانون، كالقيام ببعض التصرفات المخالفة للعادات والتقاليد والأعراف الاجتماعية والقيم السائدة في ذللك البلد. ومع ذللك، يصعب تحديد الانحراف بدقة كونه ظاهرة اجتماعية معقدة متعددة الجوانب وتختلف معاييرها باختلاف المجتمعات والأشخاص ثبعاً لاعتبارات عدة، منها: - من الصعب اعتبار سلوك ما إجرامياً أو منحرفاً ما لم يحرّمه ويجرّمه القانون. 
- قد لا يجرم القانون سلوكاً معيناً ولكنه ييقى في نظر المجتمع، أو كثير من الناس على الأقل، سلوكاً

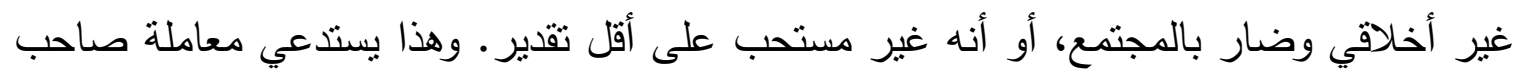
السلوك معاملة خاصة من الناحيتين السلوكية والبيئية. - عدم النضج الفكري والقدرة على التمييز والإدراك لدى صناحب السلوك غير السوي.

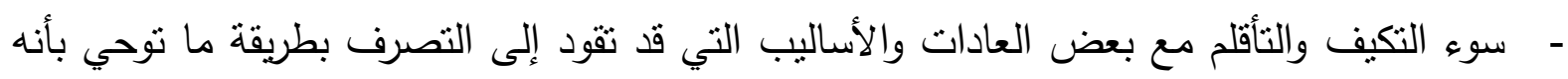

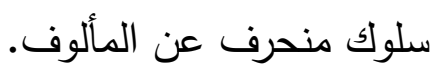

والانحراف الاجتماعي بشكل عام هو ظاهرة اجتماعية خطيرة قد تتذر باحتمال ارتكاب المنحرفين "المحترفين"

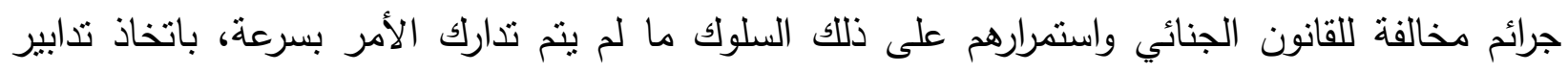

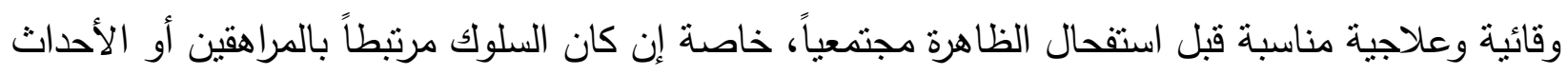
أو صغار السن.

وقد عرف المؤتمر الأول للأمم المتحدة المنعقد في جنيف عام 1900 الحدث المعرض للانحراف بالمفهوم

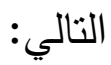
"إن الحدث المعرض للانحراف هو شخص يقل عمره عن سن محددة، يناظر عادة الحد الأقصى لسن

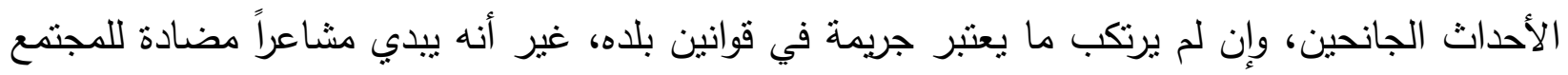

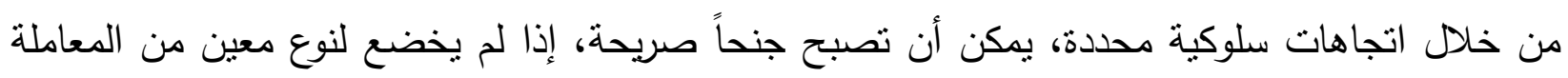

\section{عوامل الانحراف الاجتماعي من وجهات نظر مختلفة} 1

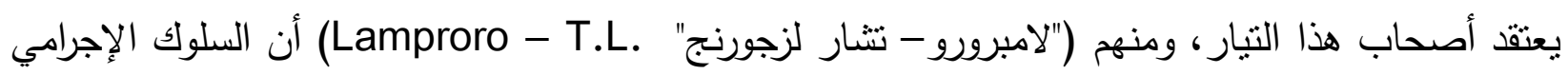

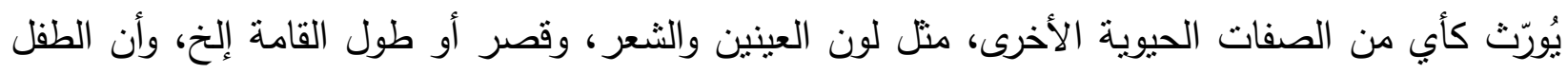

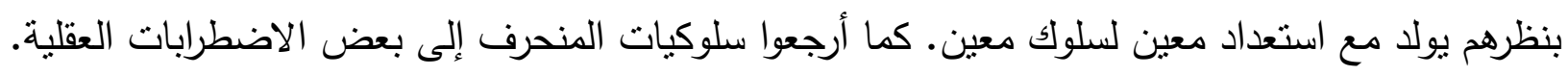

$$
\text { 2) عوامل نفسية وجسدية (نفسدية): }
$$

يرى أصحاب هذا التيار أن سلوك المنحرف يظهر نتيجة اضطرابات نفسية مختلفة لا يوجد بينها أب شبه أو

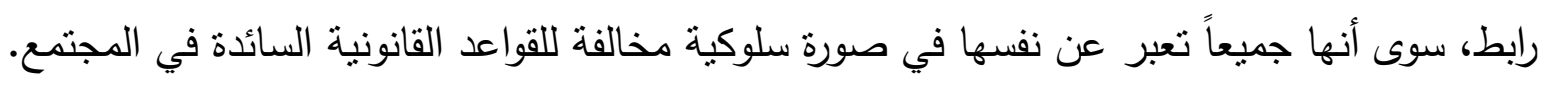




\section{3) عوامل اجتماعية وبيئية:}

يرى أصحاب هذه المدرسة أن السلوكيات المنحرفة مرتبطة بعوامل اجتماعية وطبيعية مختلفة، منها:

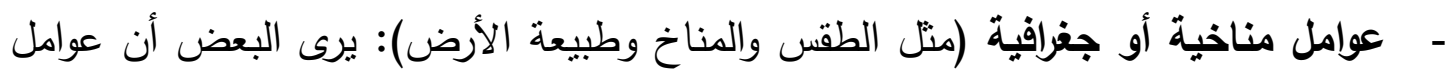

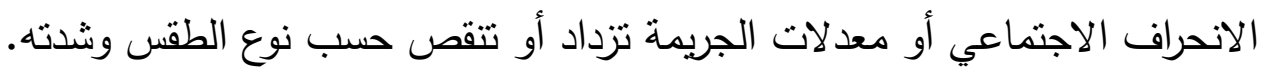

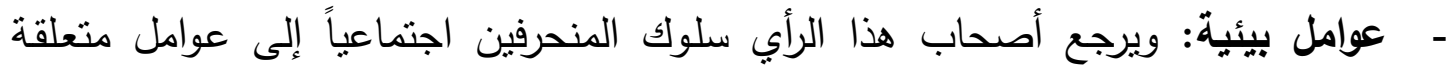

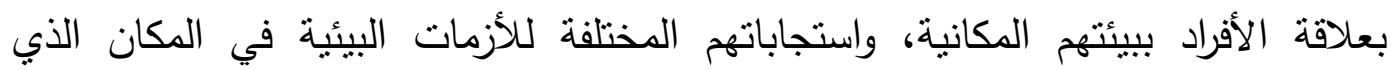
يعيشون فيه، والتفكك الأسري، وأساليب الضبط الاجتماعي، والكتافة السكانية، والتذهور المادي، والتلوث السمعي والبصري إلخ). - - التقدم الصناعي والتقتي: يرى أصحاب هذه المدرسة أن بعض أنواع الانحراف الاجتماعي

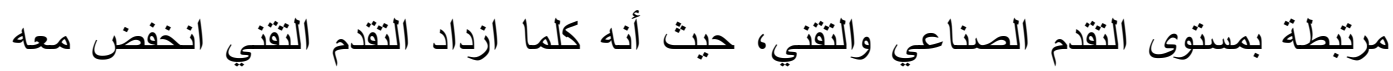

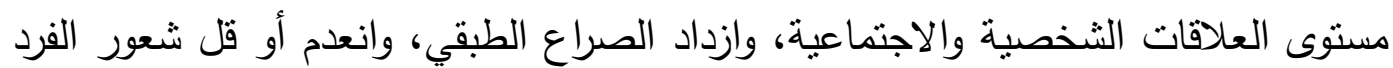
بالاطئنان والاستقرار النفسي والاجتماعي الذي يقود إلى ارتكاب بعض السلوكيات

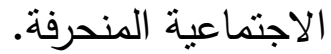

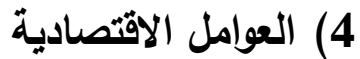

يحاول أصحاب هذا التيار ربط السلوك المنحرف أو الجرائم الاجتماعية بالحالة الاقتصادية للفرد والمجتمع بشكل عام، مثل الكساد، أو الرخاء، وقانون العرض والطلب، إلخ. 5) العوامل الأسرية

يرى أصحاب هذه المدرسة أن الاضطرابات الأسرية هي من أهم العوامل التي نساعد على انحراف الصغار

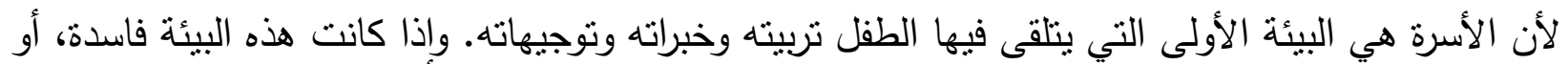
مضطربة فإن الصغير يختل سلوكيا فيما بعد.

\section{بعض ملامح السلوك الاجتماعي التي تحتاج إلى رعاية}

يعي أغلب الناشئة أثناء دخولهم مرحلة المراهقة بما يدور حولهم، ولذلك فهم يتميزون بخصائص معينة، منها: 
الثعور بالإهانة و الخجل والارتباك عندما يقومون بأفعال لم يكونوا يعلمون من قبل أنها مسيئة لمن حولهم

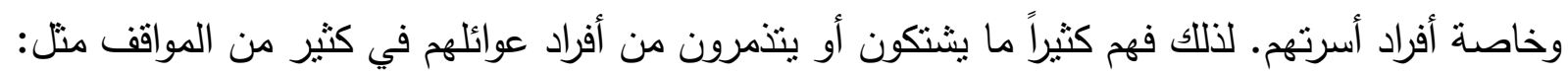
- الأخت التي تبدي المزيد من الترتيب المبالغ فيه في هندامها أو التي نقرأ المجلات والجرائد

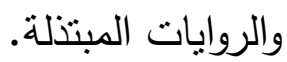

- - الأخ الصغير الذي لايتوقف عن الصراخ.

- - الأب الذي يضحك أو يقهقه بصوت مرتفع.

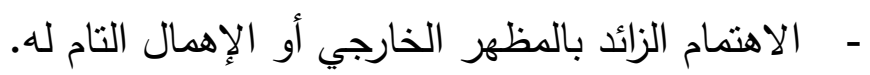

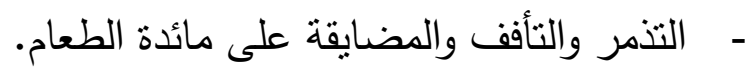

- تقبل الوالدين لمجريات الحياة: يشعر بعض الأهل بالمضايقة والقلق مع عجزهم عن تقبل

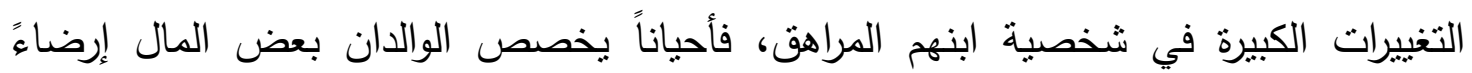
لأبنائهم غير أنهم يقعون في حالة من الحيرة والتتاقض بين تحقيق رغبة الأبناء والبقاء ضمن لئن

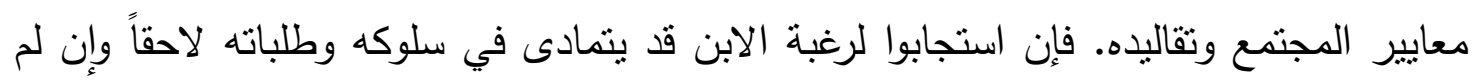

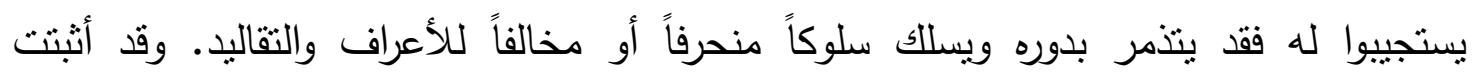

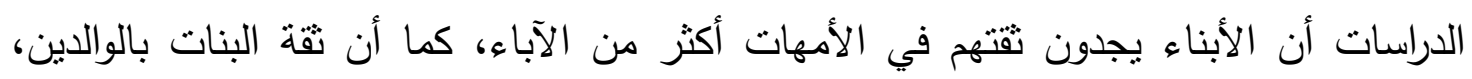
خاصة الأمهات، أكثر مما هي عند الذكور ـ وللتقة المتبادلة نتائج إيجابية على الاستقرار العاطفي

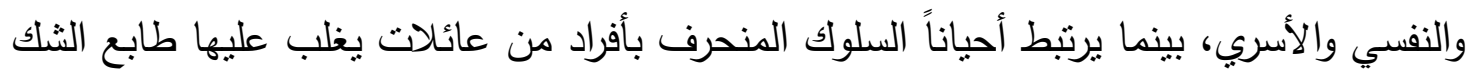
والخصام وانعدام التقة والتواصل بين الآباء والأبناء.

\section{بعض مظاهر التسلط الأبوي على الأبناء:}

هناك الكثير من الأقوال والأفعال التي تعكس رغبة تسلط أو تأناء تأثثر الآباء على أبنائهم، الأمر الذي ينعكس على سلوكهم وتقتهم بأنفسهم، منها على سبيل المنال:

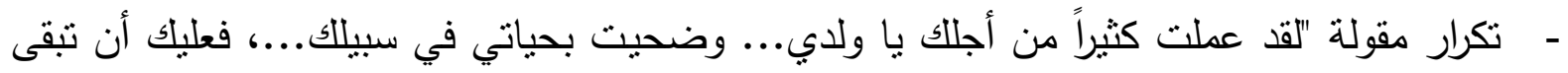
إلى جانبي وتناعدني، إلخ - وهذا أمر لاثكك فيه أنه قد يشد عاطفة الابن وشفقته على أبيه ولكنه

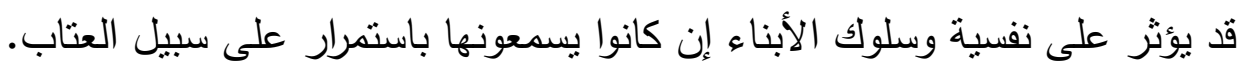

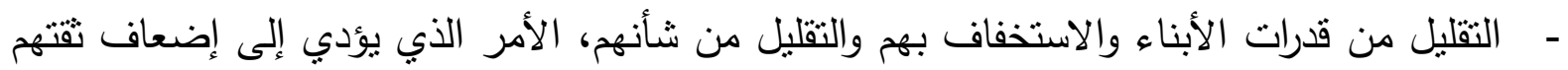
بأنفسهم لمواجهة معترك الحياة، وشعورهم بعقدة نقص وضعف يجعلهم دائمي التواكل. - محاولة كسب عطف الأبناء بادعاء العجز والوحدة. 
- - المبالغة بتدليل الأبناء وإغداق المال عليهم، الأمر الذي يشعرهم بأن الحياة سهلة ولا تحتاج إلى كفاح

أو سعي، فيتأثر سلوكهم عند أول امتحان حقيقي يخالف توقعاتهم وآمالهم.

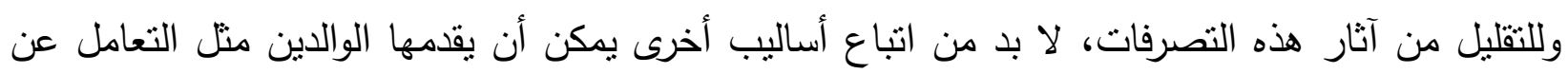

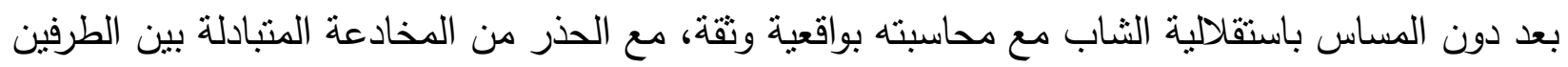

لأن مثل هذه التصرفات قد تتزلق بالثاب عن طريقه الصحيح إلى آخر أكثر وعورة وخطراً.

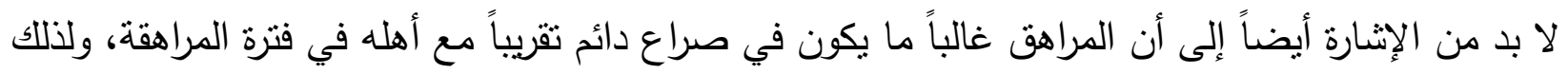

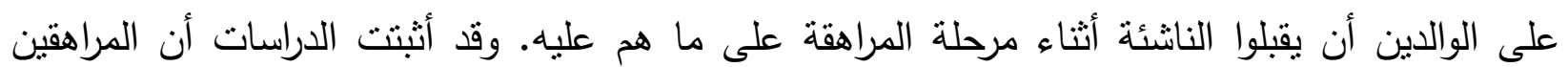
يتحسسون من أموراً كثيراً في تلك المرحلة، منها مثناً: تأنيبهم لعدم مراعاة آداب الطعام و المائدة.

متابعتهم اللصيقة والضغط عليهم في كل شاردة وواردة في مراحل الدراسة وتوبيخهم على النتائج المتحصل عليها بسبب تدني الدرجات أو النتائج الضعيفة دون تقديم

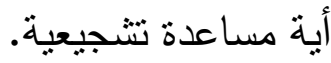
معارضنهم على سهراتهم أو صحبتهم لبعض زملائهم. التذخل في شؤونهم المالية أو إنفاقهم لمصاريفهم الثخصية. إجبارهم على تتاول أطعمة يكرهونها. تذخل الوالدين في اختيار مهن أبنائهم أو تخصصاتهم أو إصرارهم على متابعة

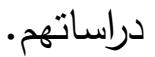
تبدو الإناث أكثر تذمراً من الأمهات من الذكور ، وذلك بسبب تدخل الأم في لباس

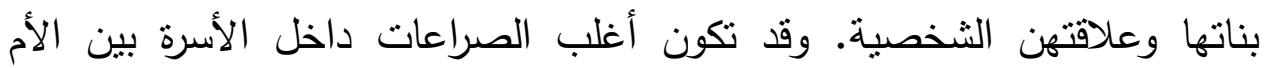

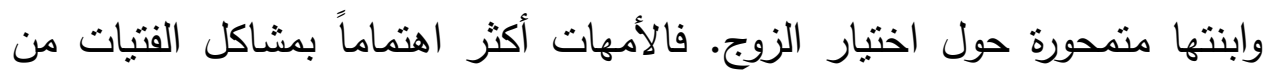

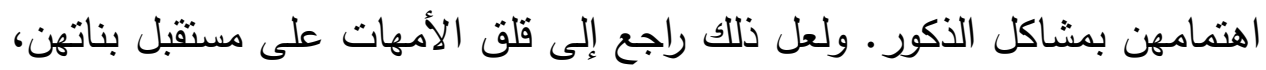

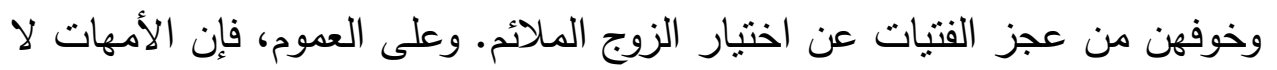
يبدين ثقة كبيرة في بناتهن ولا بقدرتهن على تحمل مسؤوليات ذواتهن بحرية.

صفات المربّي الجيد للحفاظ على سلوك جيد 1) صفات سلوكية: اللطف - الدماثة - الصدق - التواضع - المرح - التعاطف مع الآخرين. 2) صفات انضباطية: النقيد بالنظام - العدل - الموضوعية - الإيجابية - الصرامة. 
3) صفات إنتاجيـة: إثارة الاهتمام بالأثياء - المعرفة الواسعة - الثرح الجيد - مساعدة الأبناء في

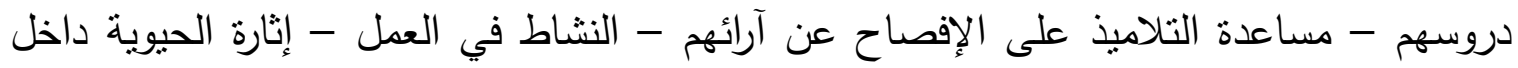

القاعة الدراسية، إلخ.

4) صفات جسديـة: الاهتمام بالمظهر الخارجي- الزينة - الصوت - البشاشة - روح المرح والمزاح، إلى حدود معينة دون إسراف أو إسفاف.

بعض العوامل التي تؤثر في انحراف السلوك الاجتماعي عند الأطفال

- - المؤسسة التربوية (المعاملة التربوية).

- وسائل الإعلام والآثار المترتبة على برامجها، التلفزة بصفة خاصة.

- - - موادي الثباب (عدم وجود أنثخاص مؤهلين يحترمون النظام التربوي).

- - السجون (اختلاط الصغار مع الكبار رغم اختلاف الجريمة).

- - السينما (أفلام الجنس والرعب) وتلفزيون الواقع والبرامج التسطيحية غير الهادفة.

\section{انحراف السلوك الاجتماعي بين النظرية و التطبيق}

من المتفق عليه حالياً أن تشكل محاكم خاصة للأحداث (الأطفال) المنحرفين والمنتوكِين للقواعد القانونية، يتولاها قضاة مؤهلون تأهيلاً خاصاً حول كيفية التعامل معهم. وقد أنشئت أول محكمة للأحداث عام 1899 بولاية لينوي - بالولايات المتحدة الأمريكية. ومع ذلك، ليس هناك محاكم من هذا هذا النوع في جميع البلدان، كالجزائر مثناً، حيث ما يزال المنحرف يحاكم أمام المحاكم العادية.

وعموماً، تتتوع تدابير علاج السلوك الاجتماعي المنحرف عند الأطفال على الثنل التالي:

1) الملاحظة (observation): وهي الفترة التي يتولى فيها المختصون دراسة شخصية المنحرف

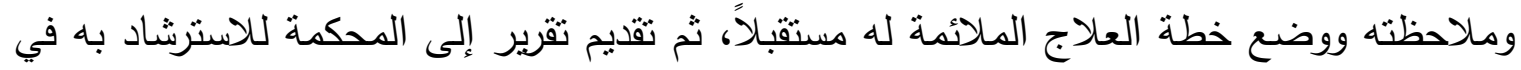
اختيار التدابير اللازمة. وعادة ما يقوم بهذه المهمة مجموعة من المرشدين الاجتماعيين والأطباء المختصين في الميادين النفسية والتربوية، ويتبعون جهات إدارية معينة، أو للمحكمة مباشرة، ويتم ملاحظة المنحرف بالطرق النالية: الين 
- - الملاحظة في البيئة الطبيعية: يقوم المختصون بإجراء المقابلات مع المنحرفين وهم في بيئته الطبيعية بغية إنجاز بعض الفحوصات والتشخيصات. - الملاحظة البيئية: حيث يقضي المنحرف نهاره في مركز الملاحظة، يعود بعدها إلى الأسرة.

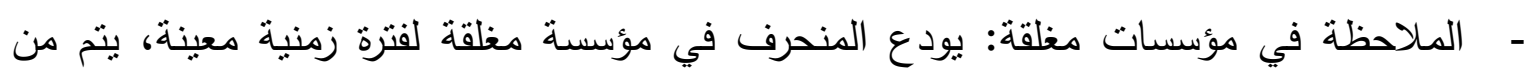
خلالها إعداد التقرير المطلوب.

2) الحجـز (détention): و المراد به وضع المنحرف تحت الحجز التحفظي قبل التصرف في شأنه، وذلك بأمر من الهيئة القضائية المختصة أو الهيئات الإدارية المعنية. ويتم الحجز بتسليم المنحرف إلى والديه أو ولي أمره، أو في مؤسسات خاصة بالحجز التحفظي على المنحرفين (الأحداث). ويتخذ هذا الإجراء إزاء المنحرفين المذنبين أو غير المذنبين (المعرضين للانحراف). 3) الاختبار القضائي (probation) و التدابير المشابهة له: الاختبار القضائي للمنحرفين هو تدبير إندير مطبق على المنحرفين المذنبين بدلاً عن الإيداع في المؤسسات التربوية، وعليه يبقى المنحرف حراً طليقاً في بيئته الطبيعية تحت إثراف موجه من مختصين في الخدمة الاجتماعية وفق خطة علاج تقوم على العلاج الثخصي. وهناك تدابير أخرى مشابهة للاختبار القضائي، إلا أنها تفقتر إلى عنصر أو أكثر من عناصره، ومن هذه التدابير : - n

الحديث parole: ويستخدم للالالة على الإفراج المشروط الذي يمنح للمنحرف على أساس انتقاء منحرف أمضى فترة من العلاج داخل المؤسسة. وهو يشبه الاختبار القضائي في كونه نوعاً من العلاج في البيئة. ضبط الواجب contrôle de devoir: وتستخدم لعلاج المنحرفين غير المذنبين (المعرضين للانحراف أو ممن في طريقهم إلى الانحراف) وهو يتعلق بالقوانين الخاصة برعاية وحماية الطفولة.

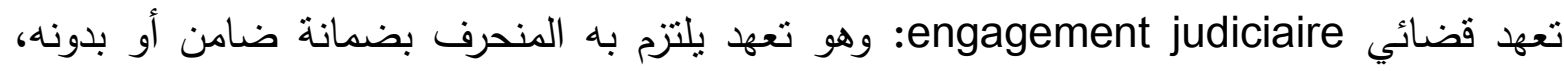
يجعل المنحرف معرضاً لتنفيذ العقوبة عليه إذا ما أخل بشرط من شروط التعهد.

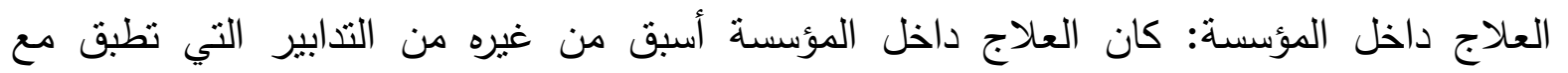
المنحرفين المذنبين، والذين تقتضي الضرورة إيداعهم إحدى المؤسسات لتلتقي مثل هذا العلاج. الرعاية اللاحقـة prévention à suivre: وهو أسلوب تكميلي للعلاج داخل المؤسسات حيث يتم التوجيه والإشراف على المنحرف الذي انتهت فترة علاجه في مؤسسة ما، لإعادة نوافقه مع المجتمع دهي

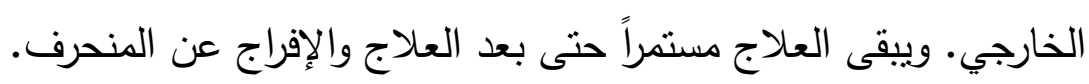




\section{المناهج السليمة للوقاية من الانحراف الاجتماعي}

تهدف برامج الوقاية من انحراف السلوك الاجتماعي عند الثباب وضياعهم إلى مواجهة العوامل والأسباب التي تؤدي إلى ذللك الانحراف، والاهتمام بدراسة السلوك الجانح لدى المنحرفين الثباب. ولكي تؤدي برامج

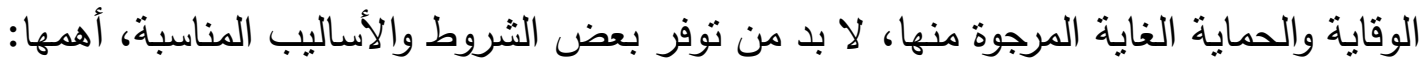

\section{- - التشـريع أو سن القوانين}

تحقق السياسة التشريعية لبلد ما، طرق الوقاية من الانحراف وذللك بسن القوانين المتعلقة بتدعيم الحياة

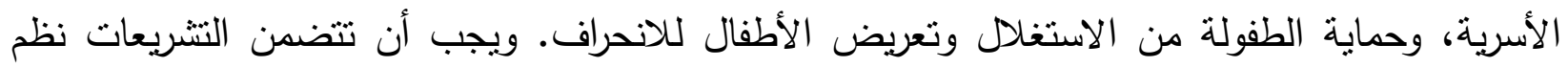

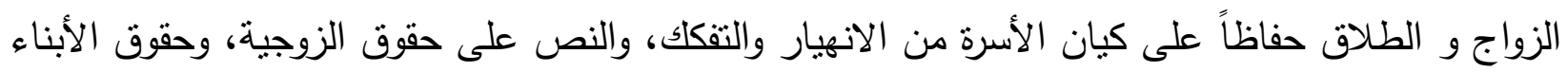

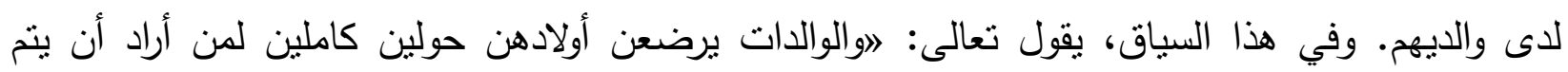

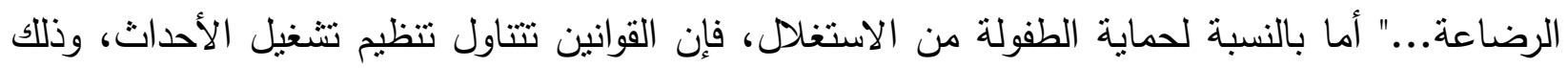
بوضع حد أقصى لساعات العمل، وتحديد المهن التي يحظر تشغيل الأحداث بها، حماية لهم من الأخطار

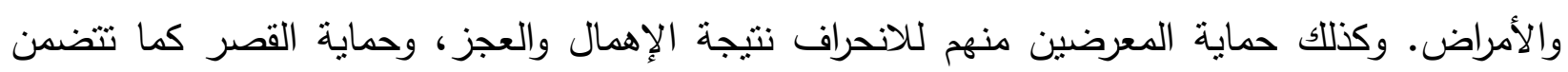
أيضاً النصوص الخاصة بعلاج الجانحين وغير الجانحين.

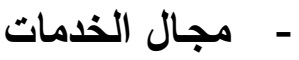

يقع على عاتق الحكومات تأمين الخدمات الاجتماعية وتحقيق أقصى مستوى من الرفاهية الاجتماعية والاقتصادية، وذلك من خلال توفير الخدمات لتحسين الظروف المعيشية وتهيئة الجو المناسب للتنشئة الاجتماعية السليمة للأطفال. وأهم هذه الخدمات:

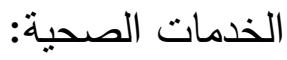

لقد أظهرت الدراسات التي أجريت لتقصي الأسباب المؤدية للانحراف أن هناك بعض الأمراض الوراثية

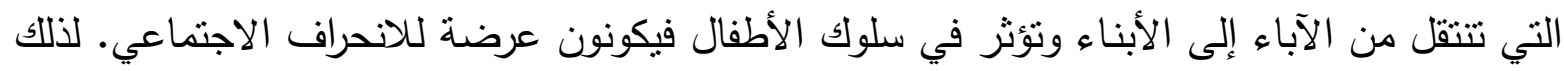

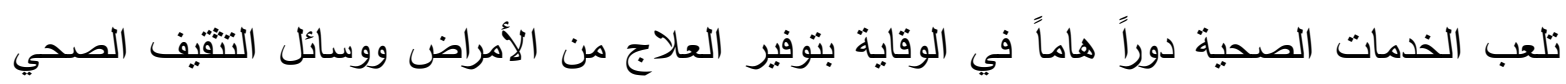
والاهتمام بأمراض الطفولة المبكرة والعمل على مواجهتها قبل استفحالها.

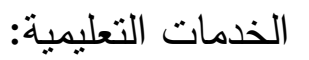

يجب أن تحدد الدولة سن التعليم الإلزامي للأطفال، لما للمدرسة من أهمية في استكمال التتشئة

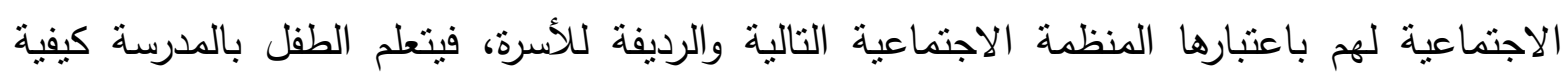


مواجهة المجتمع الخارجي، وتكوين علاقات اجتماعية سليمة، وعن طريق المدرسة يتم اكتشاف

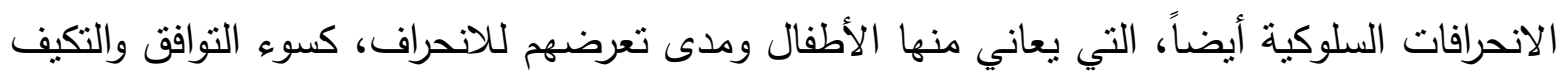
الاجتماعي، وبعض المشكلات الأخرى، كالتخلف الدراسي أو التسيب، ووضع الخطط الكفيلة بمعالجنها. خدمات أخرى:

وتتمل مثلاً تتمية المجتمع و مواجهة أثار التصنيع والتحضير واستغلال وتتظيم أوقات الفراغ من خلا

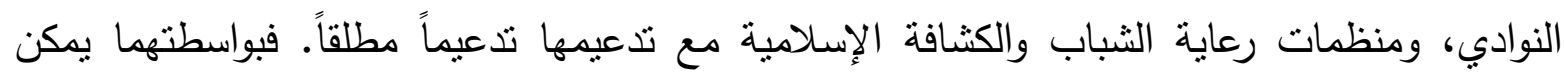

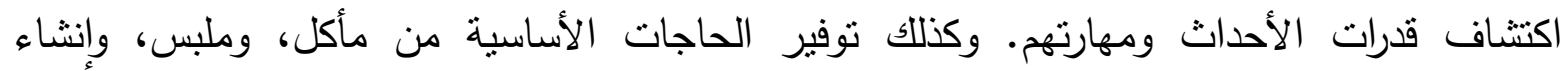
العيادات النفسية، ومواجهة الأمراض النفسدية (النفسية والجسدية) التي بصاب بها الصغار وتحسين المسنوى الاقتصادي، برفع الأجور وإقامة مراكز التكريب المهني للأحداث ممن فثنلوا في مواصلة تعليمهم العام والاهتمام بوسائل الإعلام والرقابة والتتسيق بين الخدمات وتمويلها وتوفير الخدمات الاجتماعية، وتخصيص شرطة للأحداث التي تعمل على تتفيذ القانون واحترامه، ضمن خطة دراسية تستند إلى الجانب العلمي والتربوي لمواكبة مراحل نمو الأحداث.

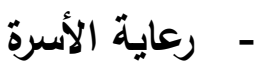

تعتبر الأسرة الدعامة الأساسية للمجتمع، والبيئة المباشرة التي يحبو فيها الحدث في طفولته المبكرة، ويكتسب

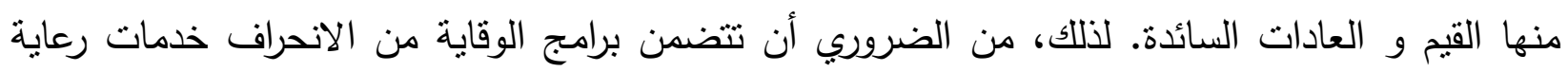

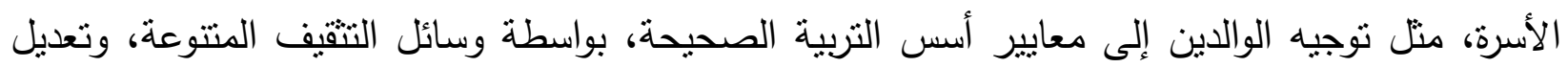

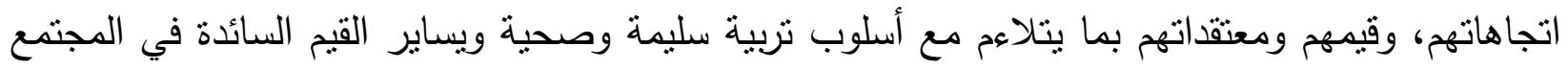
تجنباً لإحداث صدمة عند الناشئة، وكذلك مساعدته على مواجهة الظروف التهات الاقتصادية السيئة بتوفير

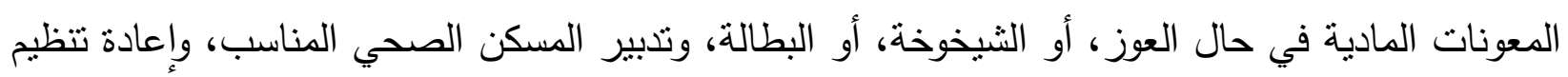

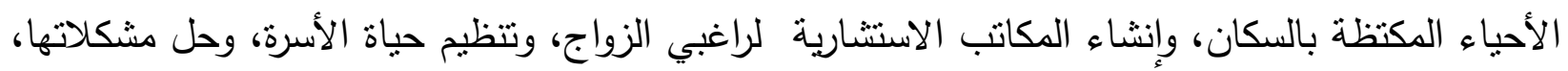

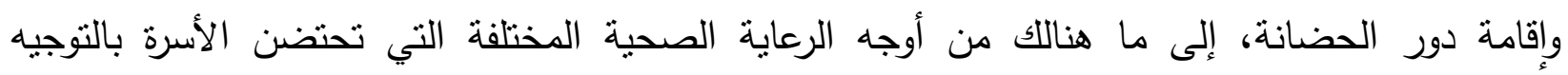
والإرشاد.

$$
\text { - }
$$


يجب أن تشمل برامج الوقاية الإحصاءات والبيانات الدقيقة التي نتير بوضوح إلى ارتفاع أو انخفاض الجرائم بين الأحداث، وتتجيع البحوث والدراسات في هذا المجال من أجل الوصول إلى حصر العوامل المسببة

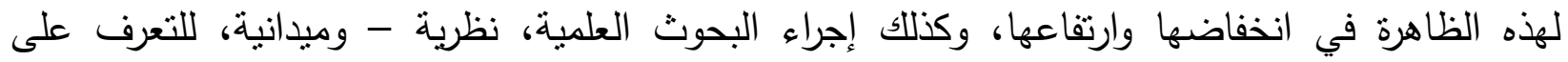
مشكلات الطفولة وحاجاتها، واقتراح برامج الوقاية، والعلاج وتعميمها وتقييمها وإنشاء مراكز البحوث المتخصصة بالتعاون مع الجامعات.

\section{References}

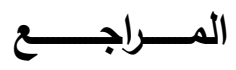

• سمير نعيم - الدراسة العلمية للسلوك الاجتماعي- دار التأليف - ص 27 ـ 1969 م القاهرة. يس السيد - مشكلة التعريف الاجتماعي للجريمة - مقال - عدد 03- م / 2 المجلة الجنائية القضائية - المركز القومي للبحوث الاجتماعية و الجنائية القاهرة. • محد عارف (مترجم)- الوقاية من جناح الأحداث - من مطبوعات وزارة الثئون الاجنماعية - ص 127 - 1963 - القاهرة. • محمد نجيب حسين - دراسة تثريعية مقارنة في معاملة الأحداث المشردين - ص 24 - 1963 - 1963 - القاهرة.

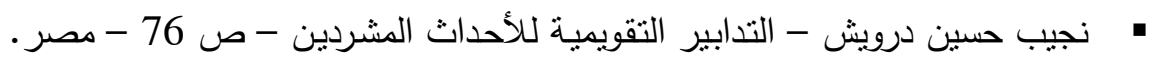

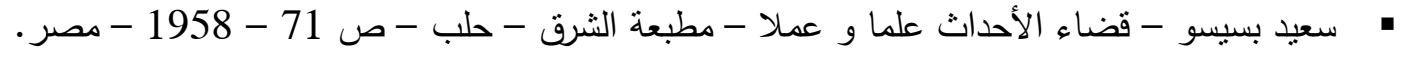
• تقارير المؤتمر المقدمة بتاريخ 24 و 94/10/25 حول الطفولة ولأحداث الجزائر العاصمة. • المؤتمر الأول للمنظمة الوطنية لجمعيات رعاية الثباب - بتاريخ: 24 و 25 أكتوبر 1994 الجزائر. 